\title{
The influence of self-talk technique for male hockey goalkeeper
}

\author{
Mohar Kassim*, Izham Md Isa \\ Centre for Coaching Science, National Defence University of Malaysia, Kuala Lumpur, Malaysia
}

\section{ARTICLE INFO}

\section{Article history:}

Received 10 July 2016

Received in revised form

18 October 2016

Accepted 6 November 2016

\section{Keywords:}

Self-talk

Mental training

Hockey goal keeper

\begin{abstract}
A B S T R A C T
This study aimed to investigate the relationship between self-talk technique in psychology of sport with individual preparation and performance among men's hockey goalkeeper. The sample involved 45 male hockey goalie selected through random sampling. The findings will analyze by using computer software, Statistical Package for Social Science (SPSS) version 21. The expected results of the analysis will indicate two important findings: First, the self-talk skills that used as a mental exercise has a significant correlation between the performances of the preparation of intermediate effects and second, it has a significant relationship between preparation and performance of intermediate effects. The results of this study are very important to help improve the performance of the national hockey team, increasing research in this field and also to serve as a guide to the national hockey team athletes, especially men's hockey goalkeeper.
\end{abstract}

(C) 2017 The Authors. Published by IASE. This is an open access article under the CC BY-NC-ND license (http://creativecommons.org/licenses/by-nc-nd/4.0/).

\section{Introduction}

The first hockey game introduced in Malaysia is in 1948. Malaysia still not independent at that time and she was still under British administration. Currently, Malaysia has a national team. Instead, every state and uniformed must have their own hockey team. However, this team still has not reached the achievement and difficult to bring the country to international levels.

Malaysian hockey players' performance seen quite lackluster; so this study will try to look at the psychological aspect of hockey goalkeeper and its impact on their performance (Omar-Fauzee et al., 2009).

According to Jaafar and Kassim (2016), in Malaysia the performances of our athletes are still below par compared to the world level athlete's performances. Only few sports such as squash, badminton, cycling and diving are capable to compete in the international level.

Hence, Kassim (2012) stated that the important of coaches requiring knowledge in the coaching process are important to build up the quality of fitness level using the norms of physical fitness. On the other hand, Kassim and Isa (2015) noted that the

\footnotetext{
* Corresponding Author.

Email Address: mohar@upnm.edu.my (M. Kassim)

https://doi.org/10.21833/ijaas.2017.04.020

2313-626X/C 2017 The Authors. Published by IASE.

This is an open access article under the CC BY-NC-ND license

(http://creativecommons.org/licenses/by-nc-nd/4.0/)
}

athletes are engaged in a process of learning which involves important aspects interpersonal and intrapersonal skills. This is supported by Kassim and Berahim (2015), stated that a conducive learning environment is also important as well as giving them a reward if they achieve excellence.

Through the study of sports psychology, psychological factors can be studied with regard to helping athletes succeed in a competition. Such studies have been carried out by Blumenstein and Lidor (2008) and Samulski and Lopes (2008) studied the relevant scientific knowledge about the psychological factors that influence and are associated with an increased performance of athletes at Olympic level.

On the other hand, the physical health, strategy and tactical are important aspects in sport. In order to be successful, athletes must make sure their physical and mental health is fit (Jaafar and Kassim, 2016). In short, Jaafar and Kassim (2016) stated that the subjective feelings bring the discomfort to whoever facing it and may influence their performance in the games.

This study also fills an important research gap on the Malaysian hockey team since to date no research has been carried out in Malaysia on the area of goalkeeper performance. Thus, the study of the hockey goalkeeper in this study will add to the literature on goalkeeper performance in the country. The acquisition and development of hockey goalkeeper will need to be given serious attention in coaching practice and performance of the Malaysian hockey team in (Isa and Kassim, 2016). 
Apart from that, according to Kassim and Ali (2015), coach preparation has become a priority and the establishment and support of national standards for coach education provides the core for an integrated system of preparing qualified coaches. Such establishment of coaching education constantly provides a consistent framework from which coach educators and coaching practitioners may establish accountability and credibility in the coaching profession. Quality coaching would then lead to improved performance and a better overall sport experience for young footballers (Gross, 1998; Kassim and Ali, 2015).

A well laid-out long term development programme with emphasis on the development and production of individual players is necessary to continuously provide quality players not only for the national league but also to the national team (Kassim and Ali, 2015).

Through the study of sports psychology, psychological factors especially self-talk technique can be studied with regard to helping athletes succeed in a competition. Such studies have been carried out by Blumenstein and Lidor (2008) and Samulski and Lopes (2008) studied the relevant scientific knowledge about the psychological factors that influence and are associated with an increased performance of athletes at Olympic level.

These shows, participants who apply psychological training will get the same results or even less to the percentage of time during practice. Participants appear to get greater benefits from the application of music during practice (Tate et al., 2012).

For this study, the imagery technique will be test as psychology training such as mental training. The model can be established is the result of using random sampling method. Model sampling refers to the way subjects were selected for study and divided among different groups. Thus, the sampling model is subject to the data.

\section{Objectives}

The aim of this study is as follows:

- To identify the effectiveness of "self-talk" the performance of the goalkeeper.

- To compare the performance of the goalkeeper go through the mental training session and those who not go through the mental training session.

- To develop guidelines that can be used to improve goalkeeper performance.

\section{Conceptual framework}

Based on the literature on previous studies, in this study, the conceptual framework in the form as shown in Fig. 1. Sekaran and Bougie (2009) and Mahmud (2009) stated that the variable is any differentiated value. Variables are divided into independent and dependent variables in this study.

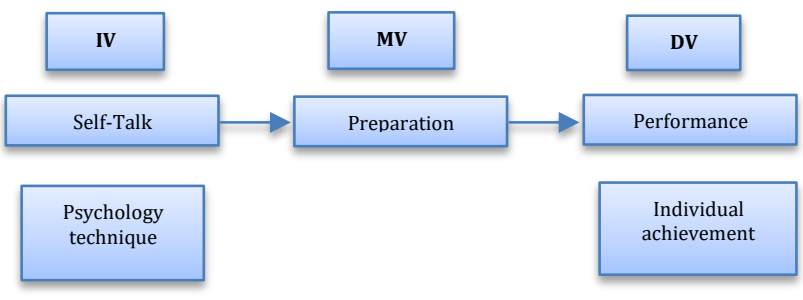

Fig. 1: Conceptual framework

\section{Research questions}

As well known, the role of the goalkeeper is very important. So, there are some issues that need to be considered when carrying out the study. Among them is to see whether the performance of the men's hockey goalkeeper will increase with the application of self-talk technique. The next question is to examine whether the techniques of self-talk provided capable of forming an effective model to serve as a guide for improving the performance of the men's hockey goalkeeper.

\section{Research interests}

The study is very important to help the national hockey team to improve their performance during competition. This study focuses only on the goalkeeper only because the role of the goalkeeper is very important in a game when dealing with opponents. In addition, the results of this study to develop a psychology model that can be used as a guideline and reference to the coach and goalkeepers whether at school or at the national level and at international level. In fact, this psychological model may also be referred by athletes besides hockey game because it involves the use of variables such self-talk and imagery to help athletes improve their athletic performance. The results of this study can also be used as an academic reference that is useful to researchers in future for research into the psychological aspects related to hockey goalkeeper is still lacking.

\section{Research methodology}

The questionnaire used survey method or descriptive method in the study as the main instrument for collecting quantitative data. A pilot study will be conducted as part of the process of data collection in which a group of individuals must answer a questionnaire that has been provided. This method is more practical because it requires the study of multiple samples. In addition, the study also used the interview as the procedures are combined together to obtain high quality data and also to avoid bias in collecting data (Creswell, 2009; Kassim, 2008).

The survey questions contained variables that were established in this study will be given to the respondents, the men's hockey goalkeeper. Interview technique also needs to be done to coaches of hockey teams to identify and verify the 
problems such studies that have been studied. This needs to be done to support the results obtained from the analysis of data in SPSS.

\section{Literature review}

The overall aim of these literature review were to stimulate further interests and ultimately research on self-talk in both the sport and exercise domains and to offer an explicit comprehensive definition of self-talk as well as suitable future directions for researchers to pursue.

Bunker et al. (1993) saw self-talk as the key to cognitive control. Meanwhile, Hardy et al. (2001) definition is rather vague and places an emphasis on thoughts in general, which makes the specific measurement of self-talk difficult such eclectic thought-oriented definitions include amongst other things, day dreams, mental imagery, and selfstatements (Hardy et al., 2001).

Besides that, an alternative definition was explained by Hackfort and Schwenkmezger (1993). Both of them proposed that self-talk was a "dialogue [through which] the individual interprets feelings and perceptions, regulates and changes evaluations and convictions, and gives him/herself instructions and reinforcement". They not only provide a selfstatement orientation, but also allude to some of the uses of self-talk.

\section{Conceptual definition}

\subsection{Self-talk}

Within the sport psychology, numerous definitions with varying have been forwarded in the self-talk literature. All the definitions range from the more infrequently proposed combining of cognitive and behavioral aspects to the more common, purely cognitive. Based on Theodorakis et al. (2001), selftalk can be manifested in verbal or non-verbal ways, in the form of a word, a thought, a smile, a frown, etc. (Chroni, 1997).

Kassim (2008) suggested that coaches who are concerned with the well-being and development of their players create a more positive learning environment. Kassim (2008) highlighted that the importance of positive environmental sources such as reward from coaches, parents, peers, and others is a key for the athletes continued involvement in sports, and coaches should be aware of how motivation can be influenced by positive environment. In this study, the coaches were aware of the importance of sustaining a positive environment and they continuously attempted to create a climate conducive to the team achieving its goals. For example, the coaches should emphasize the importance of acknowledging each player, always creating a positive environment, to avoid quarrels with the players and he made the players aware that the coaches care.
Relevant to this is the view of Kassim and Isa (2015) who argued that understanding the players' stages of learning by the coaches is an important task in training youth players. The coaches in this study paid attention to the overall well-being of their players and endeavoured to ensure they helped their players excel in their football and academic careers. As pointed by Kassim and Berahim (2015), it is important not only to develop the athletes as good players, but to build them as individuals who are potentially intelligent and dynamic people. For example, the coaches not only cared for the welfare of the players, but also the players' career after they finished their term of schooling. To these coaches, concern for the well-being of their players meant helping them excel in both their hockey and academic work.

The concern shown by the coaches to the players was appreciated by the players Kassim (2008) have stressed that athletes who were highly compatible with their coach evaluated overall behaviours more favourably than athletes who were less compatible with their coach. This means if the athletes' goals and personality are compatible with those of the coach, their interactions will be considered satisfactory and will make for a positive atmosphere. The authors observed that the concerns showed by the coaches towards these players had produced a positive attitude and team cohesion and above all, the players were happy to be with the team.

This would realize the concept of reflection on action and learning through experience (Gilbert and Trudel, 2002) which is crucial in the context of the coaching process. This means the implementation of the coach education programme for the hockey team needs to be improved, including the incorporation of practical coaching aspects in the coaching manual, the prolongation of the hockey season and the development of a formalized mentoring programme among the coaches at the national level.

In addition, many athletes have recognized abilities and power that bring the high resolution in sport performance. Most successful athletes also confessed that their success was also aided by imagery techniques.

Moreover in the view of Hausenblas et al. (1999), not only athletes but exercisers also use imagery for the purpose of improving their performance. However not all athletes are able to verbally tell about how they apply this technique. Generally, imagery is helping athletes. This was also supported by Anderson (2000). He argues that the imagery can help one to achieve the desired performance.

Since coaching is a continuous process, the coaches' style of coaching is important and this aspect is very much related to the knowledge and experience of the coaches. As far as the coaching style is concerned, there were a number of ideas held by the football coaches in this study that were related to their beliefs (Kassim and Isa, 2016).

The changes in the syllabus and contents of the coach education programme also need to be made by the Malaysian Hockey Council to include more 
practical coaching content, including the mentoring programme.

\subsection{Preparation}

Preparation is related to how people use the knowledge that has been owned for getting mentally prepared before the game and practice. However, in the present distinction between teams and individual players is the minimum, and because the excess comes from the psychological side.

Some player born as mentally strong player but like in terms of physical, mental aspects are also being trained. Coaches must also try to get everything out of their players and forces every day, so this idea is to realizing a tool that allows players to learn more about mental inventory easily and in a short time.

There are several different aspects and ways for mental preparation so there are two aspects that need attention are: mental imagery and self-talk. Most players know something self-talk and mental imagery as a concept but they do not know how to use it in practice. Calculated mental preparation is still a rather strange concept for most young players so the decision was made to approach it from a very simple way.

Mental preparation has to be practiced before the game. If the athletes are trying new techniques for the first time it would take too much energy to just focus on the preparation, and not sacrifice. That's why athletes should practice techniques of preparation before the game or in a smaller competition. The right mental preparation can last a whole day or just a few hours before the performance.

\subsection{Performance}

Performance can be describes as a discrete event where a performer showcases a specific set of developed knowledge, skills, and abilities (KSAs). Performance also intends to use the knowledge skills or abilities that are different from what they have. Aoyagi and Portenga (2010) stated "A good performance requires the development mastery and the ability to get consistent performance".

Performers rarely develop appropriate KSAs or implement them in the events performance separately. They usually have a teacher or coach, along with his teammate's co-performers and the audience.

Moreover, in general it refers to the discipline and profession of to build psychology performance has intuitive appeal to experienced practitioners. In the field of performance to build psychology practitioners still need to have special knowledge to every domain in which they choose to work (example: sports, medical, military perform high-risk jobs); for example in the context of the sport is a unique performance environments that require specialized training outside the public performance.
Future research should also continue to examine the role and involvement of more parties or agencies in the development of the coach education programme in the country

Greater importance should be placed on the review of the coach education programme to ensure the effectiveness of the programme in producing competent coaches and quality players in future (Kassim, 2008). In addition, Kassim (2008) stated that Training and competition are elements of the coaching process and become important indicators for the hard work undertaken by the players to enhance performance.

As such, the physical, tactical and technical training carried out by the coaches were meant for the players to develop their skills and prepare themselves physically and technically for national and international tournaments.

\section{Conclusion}

Overall, this study aims to identify the significant for self-talk, preparation and performance. The studies confirmed the method of constructing the instrument. After identifying variables, a pilot study should be conducted to see the effectiveness of the variables that have been set up to connect the psychological aspect and the performance of the men's hockey goalkeeper. The findings of the respondents would answer the questions of the survey will be used to analyze the relationship between the two aspects. Among other measures to be taken is through interviews with the coaches men's hockey team to get the whole picture and confirm the problem statement.

\section{References}

Anderson MB (2000). Doing sport psychology. Human Kinetics, Champaign, USA.

Aoyagi MW and Portenga ST (2010). The role of positive ethics and virtues in the context of sport and performance psychology service delivery. Professional Psychology: Research and Practice, 41(3): 253-259.

Blumenstein B and Lidor R (2008). Psychological preparation in the Olympic village: A four-phase approach. International Journal of Sport and Exercise Psychology, 6(3): 287-300.

Bunker L, Williams JM, and Zinsser N (1993). Cognitive techniques for improving performance and building confidence. In: Willaims JM (Ed.), Applied sport psychology: Personal growth to peak performance. $2^{\text {nd }}$ Edition, Mountain View, USA.

Chroni S (1997). Effective verbal cues make the skier's and coach's lives easier. American Ski Coach, 18(19): 13-14.

Creswell JW (2009). Research design: Qualitative, quantitative, and mixed methods approaches. $3^{\text {rd }}$ Edition, Sage Publications, Los Angeles, USA.

Gilbert WD and Trudel P (2002). Learning to coach through experience: Reflection in model youth sport coaches. Journal of Teaching in Physical Education, 21(1): 16-34.

Gross JJ (1998). Antecedent-and response-focused emotion regulation: divergent consequences for experience, expression, and physiology. Journal of personality and social psychology, 74(1): 224-237. 
Hackfort D and Schwenkmezger P (1993). Anxiety. In: Singer RN, Murphey M, and Tennant LK (Eds.). Handbook of research on sport psychology: 328-364. Macmillan Press, New York, USA.

Hardy J, Hardy L and Hall CR (2001). Self-talk and perceived exertion in physical activity. In the Meeting of the Association for the Advancement of Applied Sport Psychology, Orlando, USA.

Hausenblas HA, Hall CR, Rodgers WM, and Munroe KJ (1999). Exercise imagery: Its nature and measurement. Journal of Applied Sport Psychology, 11(2): 171-180.

Isa IM and Kassim M (2016). Can imagery technique enhance the goalkeeper performance?. Journal and Scientific Research and Development, 3(4): 60-65.

Jaafar Z and Kassim M (2016). The effectiveness of imagery training on anxiety levels and performance amongst athletes in archery. Australian Journal of Basic and Applied Sciences, 10(11): 207-213.

Kassim M (2008). A qualitative study of the relationship between the knowledge and behaviour of coaches in two football academies in Malaysia. Ph.D. Dissertation, Loughborough University, Loughborough, UK.

Kassim M (2012). The Acquisition of knowledge by the coaches: Can qualitative approach help?. Jurnal Sains Sukan dan Pendidikan Jasmani, 1: 24-34.

Kassim M and Ali NR (2015). An effective coaching through 'coaching model'. Journal of Scientific Research and Development, 2(13): 158-164.
Kassim M and Berahim M (2015). Football training development programme under-15 years old State Level. Australian Journal of Basic and Applied Science, 10(11): 133-137.

Kassim M and Isa MI (2015). The importance of psychological factors for male hockey goalkeepers. Australian Journal of Basic and Applied Sciences, 9(34): 98-102.

Mahmud Z (2008). Handbook of research methodology: a simplified version. University Publication Centre (UPENA), UiTM, Shah Alam, Malaysia.

Omar-Fauzee MS, Daud WRBW, Abdullah R, and Rashid S (2009). The effectiveness of imagery and coping strategies in sport performance. European Journal of Social Sciences, 9(1): 97 108.

Samulski DM and Lopes MC (2008). Counseling Brazilian athletes during the Olympic Games in Athens 2004: Important issues and intervention techniques. International Journal of Sport and Exercise Psychology, 6(3): 277-286.

Sekaran U and Bougie R (2009). Research Methods for Business: A Skill Building Approach. $5^{\text {th }}$ Edition, John Wiley \& Sons, Chichester, UK.

Tate AR, Gennings C, Hoffman RA, Strittmatter AP, and Retchin SM (2012). Effects of bone-conducted music on swimming performance. Journal of Strength and Conditioning Research, 26(4): 982-988.

Theodorakis Y, Chroni S, Laparidis K, Bebetsos V, and Douma I (2001). Self-talk in a basketball-shooting task. Perceptual and Motor Skills, 92(1): 309-315. 